\title{
Temperature sensitivity to the land-surface model in MM5 climate simulations over the Iberian Peninsula
}

\author{
Sonia Jerez ${ }^{1}$, Juan P. Montavez ${ }^{1 *}$, Juan J. Gomez-NAVArro ${ }^{1}$, Pedro Jimenez-Guerrero ${ }^{1}$, \\ Jose M. JIMENEZ ${ }^{2}$ and Jesus F. GonZALEZ-ROUCO ${ }^{2}$ \\ ${ }^{1}$ Departamento de Física, Universidad de Murcia, Spain \\ ${ }^{2}$ Departamento de Astrofisica y CC. de la Atmosfera, Universidad Complutense de Madrid, Spain
}

(Manuscript received October 27, 2009; in revised form August 17, 2010; accepted August 17, 2010)

\begin{abstract}
Three different Land Surface Models have been used in three high resolution climate simulations performed with the mesoscale model MM5 over the Iberian Peninsula. The main difference among them lies in the soil moisture treatment, which is dynamically modelled by only two of them (Noah and Pleim \& Xiu models), while in the simplest model (Simple Five-Layers) it is fixed to climatological values. The simulated period covers 1958-2002, using the ERA40 reanalysis data as driving conditions. Focusing on near-surface air temperature, this work evaluates the skill of each simulation in reproducing mean values and temporal variability, by comparing the simulations with observed temperature series. When the simplest simulation was analyzed, the greatest discrepances were observed for the summer season, when both, the mean values and the temporal variability of the temperature series, were badly underestimated. These weaknesses are largely overcome in the other two simulations (performed by coupling a more advanced soil model to MM5), and there was greater concordance between the simulated and observed spatial patterns. The influence of a dynamic soil moisture parameterization and, therefore, a more realistic simulation of the latent and sensible heat fluxes between the land and the atmosphere, helps to explain these results.

\section{Zusammenfassung}

Drei verschiedene Landoberflächenmodelle wurden verwendet, um drei hochauflösende Klimasimulationen für die iberische Halbinsel mit Hilfe des mesoskaligen Modells MM5 durchzuführen. Der Unterschied der drei Modelle liegt hauptsächlich in der Behandlung der Bodenfeuchtigkeit, die in zwei der Modelle (Noah und Pleim \& Xiu) dynamisch modelliert wird, während sie im einfachsten Modell (Simple Five-Layers) durch klimatologische Größen festgelegt ist. Die simulierte Zeitspanne reicht von 1958 bis 2002, wobei als Simulationsbedingungen die Reanalyse-Daten ERA40 dienen. Indem wir uns auf bodennahe Lufttemperaturen konzentrieren, wird in dieser Arbeit die Qualität jeder einzelnen Simulation, welche die beobachteten Jahreszyklen, die räumlichen Strukturen und die zeitlichen Veränderungen der Temperatur wiedergibt, durch den Vergleich mit instrumentellen Monatsmitteltemperaturserien ausgewertet. Die einfachste Simulation zeigt die größte Diskrepanz zu den Beobachtungen der Sommersaison, da die Temperaturmittel und die zeitlichen Veränderungen der Temperatur maßgeblich unterschätzt wurden. Diese Schwächen wurden in den beiden anderen Simulationen (in denen ein fortschrittlicheres Bodenmodell an MM5 gekoppelt wurde) zum größten Teil beseitigt und eine höhere Übereinstimmung zwischen simulierten und beobachteten räumlichen Strukturen wurde erreicht. Der Einfluss einer dynamischen Bodenfeuchtigkeitsparametrisierung und dadurch eine realistischere Simulation des latenten Flusses und der Wärmestromdichte zwischen Boden und Atmosphäre begründen diese Ergebnisse weitgehend.
\end{abstract}

\section{Introduction}

High resolution climate simulations are in great demand for several applications. The use of Regional Circulation Models (RCMs) permits high spatial resolutions at a reasonable computational cost, improving the representation of regional features, such as orography, land use, vegetation, etc., that are not faithfully represented in General Circulation Models (GCMs). Global warming projections at regional scales for impact studies (BOO et al., 2006; IM et al., 2008; LiONELLO et al., 2008) or hindcast experiments for evaluating renewable energy resources (FRANK and LANDBERG, 1997; PAN et al.,

\footnotetext{
*Corresponding author: Juan P. Montavez, Departamento de Física, Universidad de Murcia, Edificio Cioyn, Campus de Espinardo, 30100 Murcia, Spain, e-mail: montavez@um.es
}

2004; PRYOR et al., 2005) are some examples of RCMs applications. Such confidence demands rigorous work to evaluate, on the one hand, the skill of RCMs to accurately reproduce the observations, and by the other hand, the sources of uncertainty and the way they might be overcome for future improvements.

The reliability of RCMs depends on several influential factors, such as spatial configuration and nesting strategies (JUANG and HONG, 2001; BECK et al., 2004), soil specification (PIELKE, 2001), and the choice of physics parameterizations (FERNANDEZ et al., 2007). Land surface-atmosphere interaction is one of the processes that is parameterized in RCMs (STENSRUD, 2007).

The key role of the Land-Surface Model (LSM) for weather forecast is already well known (KOSTER et al., 


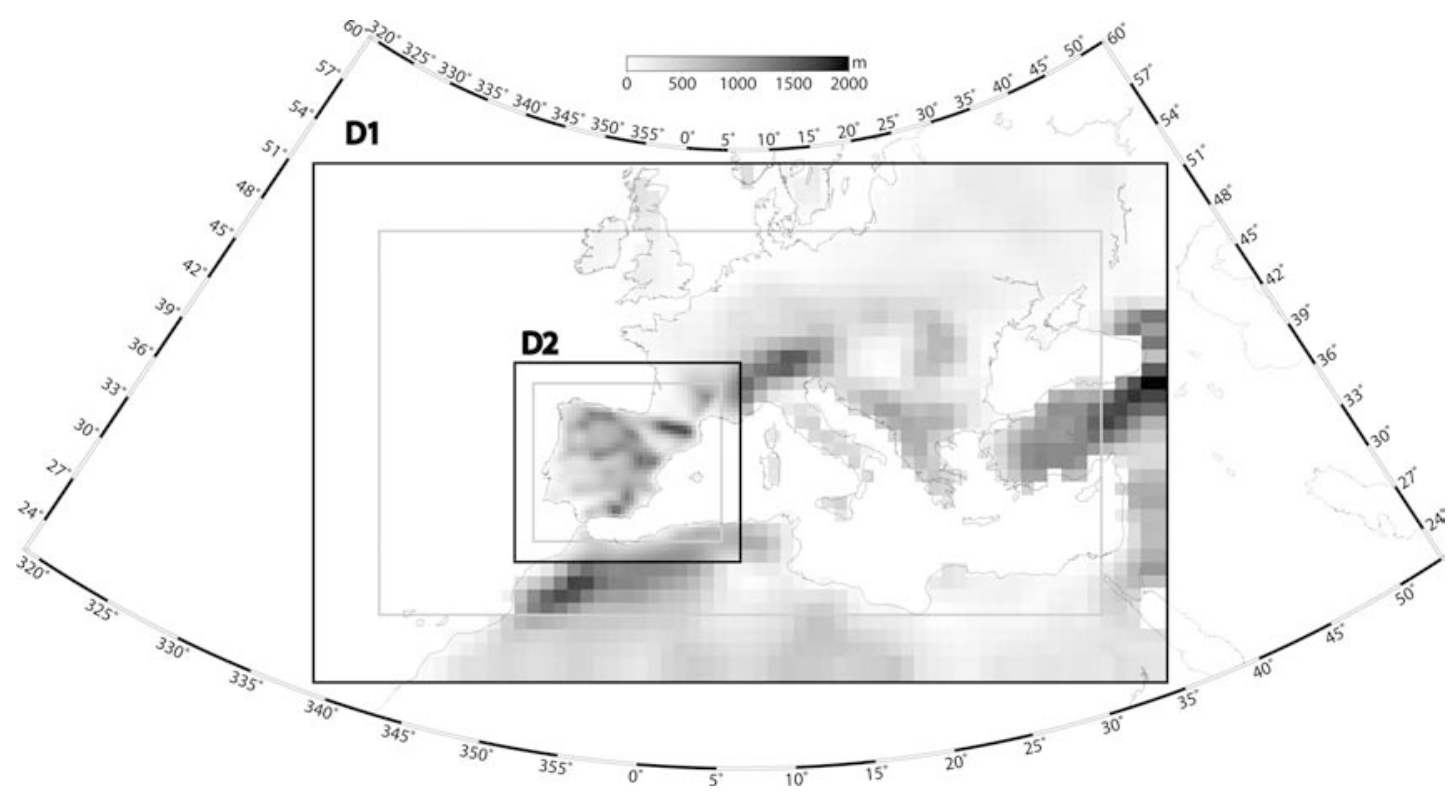

Figure 1: Domains used in the simulations. Mother domain, D1, with a resolution of $90 \mathrm{~km}$, and inner domain, D2, with a resolution of 30 $\mathrm{km}$. Black borders are the actual borders of the domains, and gray lines are the borders once the blending area (first five points from the border) is removed. The topography is represented by shadows.

2004; LUO et al., 2007; ZHANG et al., 2008), and efforts have been made, since the first implicit approach representing the surface energy balance and hydrology (MANABE, 1969), to attain a more realistic modelling of the processes through which the land surface influences climate (PITMAN, 2003). Such processes involve down-surface heat and moisture transfer and distribution, root absorption of water, direct evaporation and evapotranspiration, subsurface drainage and superficial runoff, and the partition of the surface available energy into latent and sensible heat transfer to atmosphere, which is lastly controlled by the former.

The "Project for Intercomparison of Land-surface Parameterization Schemes" (PILPS) widely reported the importance of the soil forcing in GCM simulations, particularly as regards soil moisture initialization and modelling (HENDERSON-SELLERS et al., 2003; IRANNEJAD et al., 2003). Other works assess more specifically the influence of the LSM in regional simulations of near surface-air temperature. SENEVIRATNE et al. (2006) pointed to the relationship between the enhancement of summer temperature variability projected for central and eastern Europe and feedbacks between land surface and the lower atmosphere. FISCHER et al. (2007) revealed that land-atmosphere coupling plays a crucial role when studying the evolution of recent European summer heat waves. MIAO et al. (2007) compared meteorological simulations performed by coupling different LSMs to the RCM MM5 (GRELL et al., 1994) obtaining important differences in the model performance, especially when simulating urban heat islands. These findings emphasize the non-negligible impact and the amplifying effect of soil moisture-temperature feedback. Nevertheless, to our knowledge, there is a lack of studies dealing with the sensitivity to the land surface model at both regional and climatic scales.

This work analyzes the skill of regional simulations performed with the RCM MM5 (GRELL et al., 1994) to accurately reproduce the climatology of the Iberian Peninsula (IP), focusing on 2-meter temperature (T2M), when different LSMs are employed. MM5 (GRELL et al., 1994) allows three different soil parameterizations: Simple Five-Layers LSM (SFL; DUDHIA, 1996), Noah LSM (Noah; CHEN and DUDHIA, 2001a,b) and Pleim\&Xiu LSM (P\&X; XIU and PLEIM, 2001). Differences among them come from the number of processes they solve and the approach they follow. The treatment of the soil moisture content is an outstanding characteristic of each one. While SFL prescribes the available soil moisture to fixed values, the two others model it dynamically using different methodologies. Comparison between analogous simulations, which differ in the LSM used, and observations should provide some insight about the influence of the different LSM formulations.

The Iberian Peninsula is a likely scenario for this kind of study due to its climatic heterogeneity: from the Mediterranean climate characterized by warm and dry summers with convective-predominant precipitation and cold and humid winters with large-scale induced precipitation, to milder winters and wetter summers toward the north and west (FONT-TULLOT, 2000). These characteristics allow the response to the land-atmosphere coupling to be evaluated under diverse conditions and, therefore, the most affected regions and seasons to be detected. It was to be expected that the more complex LSMs would be able to capture such differences and have a major positive influence during summer over 
the southern driest areas of the IP (FERNANDEZ et al., 2007).

This work is structured as follows. Section 2 describes the experiments and data, and provides a detailed description of the LSMs employed in the simulations. In section 3 the results are shown, focusing on the ability of the simulations to reproduce the annual cycle and the temporal variability of the temperature series. Also, the underlying processes that cause the differences between simulations are investigated. Finally, conclusions and some comments are presented in section 4 .

\section{Experiments and data}

Three different high resolution climate simulations over the IP were carried out using a climate version of the MM5 mesoescalar model (GRELL et al., 1994). MM5 has been widely used in climate research (ZHU and LiAnG, 2007; MonAGHAN et al., 2008), and several studies support its good performance over the Iberian Peninsula (FERNANDEZ et al., 2007; GoMEZNAVARRO et al., 2010). The simulated period is 19582002, using the ERA40 reanalysis (UPPALA et al., 2005) as driving conditions. The spatial configuration for the runs consists of two two-way nested domains (Figure 1), reaching a resolution of $30 \mathrm{~km}$ over the inner domain (D2), which covers the whole IP. The mother domain (D1), with a resolution of $90 \mathrm{~km}$, is displaced toward the east in order to catch the influence of the Mediterranean Sea on the IP climate (FONT-TULLOT, 2000). Vertically, 24 sigma levels up to $100 \mathrm{mb}$ are considered.

The main difference among the three simulations setups lies in the LSM employed, SFL, Noah or P\&X (described below), but also in the Planetary Boundary Layer (PBL) parameterization used, since its choice is limited by the LSM-PBL couplings permitted. In both SFL and Noah simulations, the non local MRF PBL scheme is used (HONG and PAN, 1996), while the P\&X simulation demands the local Pleim-Chang (P\&C) PBL parameterization (PLEIM and XIU, 1995; XIU and PLEIM, 2001). The rest of the physic configuration of MM5 is common for the three simulations: Grell cumulus parameterization (GRELL, 1993), Simple Ice for microphysics (DUDHIA, 1989) and RRTM radiation scheme (MLAWER et al., 1997). This choice follows the criterion of minimizing the computational cost, based on the results of FERNANDEZ et al. (2007) which indicated that no single physical setup provides the best performance for every season and area.

The time integration approach to perform the simulations consists of splitting the whole period into subperiods of 15 consecutive years, which are then integrated by continuous runs with a spin-up period of four months. The outputs during this period, integrated only to reach dynamic equilibrium, are ignored. Model outputs are recorded every 6 hours for D2 and 12 hours for D1.
The simulations are evaluated by comparison with an observational data base (referred to as OBS) which consists of monthly mean temperature series covering the whole simulated period, obtained from an observational network that includes 55 meteorological stations spread all over the IP (see locations in Figure 2). This data base was provided by the Spanish National Agency of Meteorology (AEMET) and the National Meteorological Institute of Portugal. When confronting the simulations and observations, a spatial interpolation is performed from the grid points of the simulations to the points of the observational network. Such interpolation consists of a distance-weighted mean involving the grid points that fall inside a circle centered at the selected point of the observational network, with a radius equal to twice the minimum distance between the former point and any grid point.

The main characteristics of the different LSMs are:

- Simple Five-Layers Soil Model (SFL; DudHIA, 1996). This model uses five soil layers with thicknesses, from top to bottom, of 1, 2, 4, 8 and $16 \mathrm{~cm}$. Below the bottom level, at $31 \mathrm{~cm}$, the substrate temperature is kept constant in a 32-cm thick layer. The transfer of heat follows the one-dimensional simple diffusion equation (the heat flux is linearly proportional to the temperature gradient). The flux convergence is proportional to heating. The parameters that appear in such formulations (soil's thermal diffusivity and specific heat capacity) are constant in time, depending only on the landuse/vegetation category which is specified from 25-category $30^{\prime \prime}$ data from USGS version 2 land cover data (LOVELAND et al., 2000). Available soil moisture is also determined by such classification and remains constant during the whole simulated period. There are two sets of soil moisture values, one for summer and one for winter, but just one of them is used depending on the initial date of the runs. If it falls between 15 April and 15 October, the summer values are used; if it falls between 15 October and 15 April, the winter values are used. Thus the summer values are used in the SFL simulation, since it was began on 1 September. Neither runoff nor canopy transpiration processes are considered in this LSM. Snow cover is treated as any other land use category.

- Noah Land Surface Model (Noah; CHEN and DudHIA, 2001a,b). This model counts on four soil layers with thicknesses of 10, 30, 60 and $100 \mathrm{~cm}$, and an additional canopy layer. The prognostic variables are soil moisture and temperature in the soil layers, water stored on the canopy and snow stored on the ground. The total soil depth is $2 \mathrm{~m}$, with the root zone in the top $1 \mathrm{~m}$ of soil. The lower $1-\mathrm{m}$ soil layer acts as a reservoir with gravity drainage at the bottom. The ground heat flux is again controlled by the usual diffusion equation for soil temperature, but in this model heat capacity and thermal conductivity are formulated as functions of the 


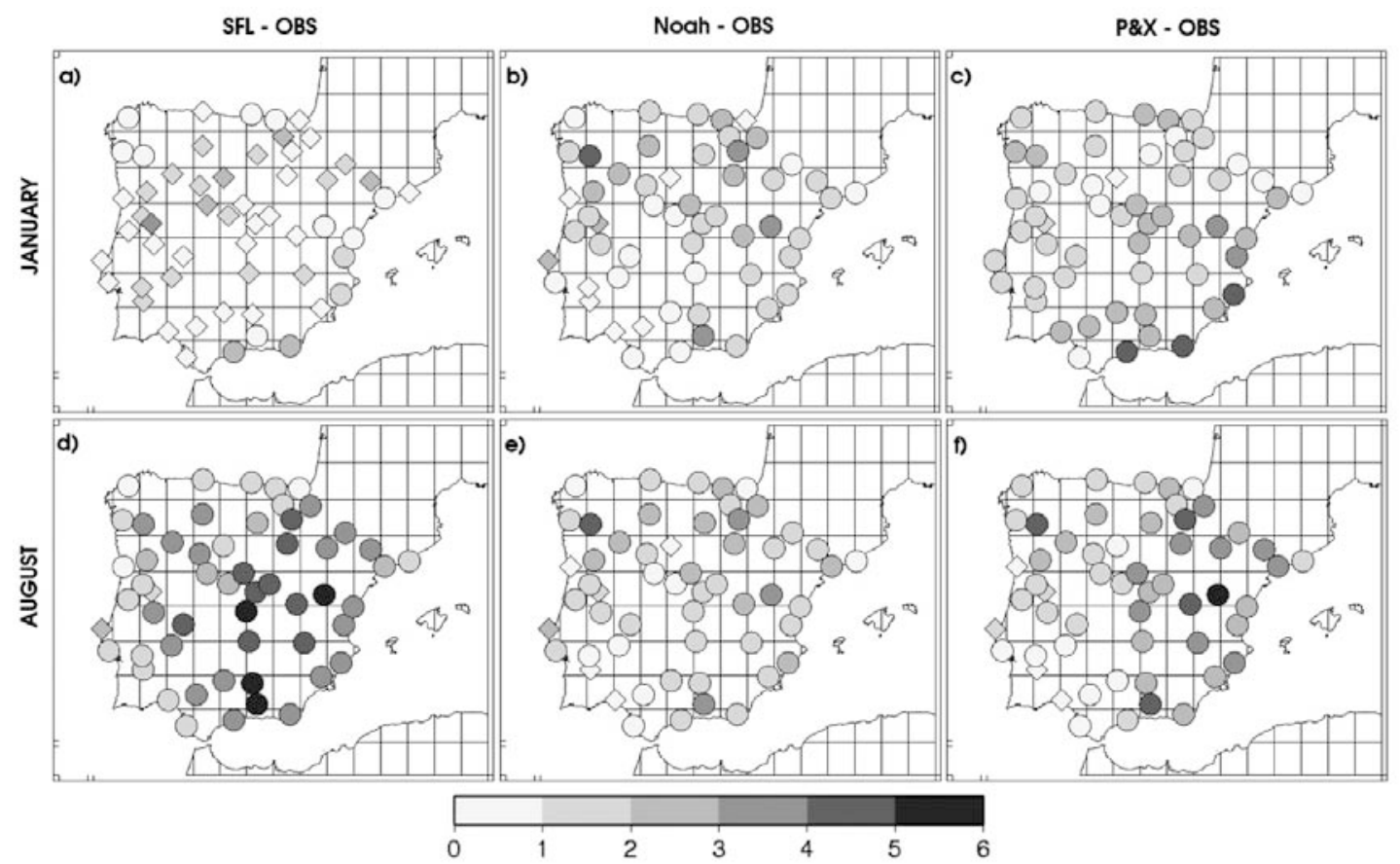

Figure 2: Differences between simulations and observations in the T2M climatologies of January (top) and August (bottom). SFL minus OBS (left column), Noah minus OBS (central) and P\&X minus OBS (right). Positive biases are represented by diamonds and negative by circles, in Kelvin. Averaged period 1958-2002.
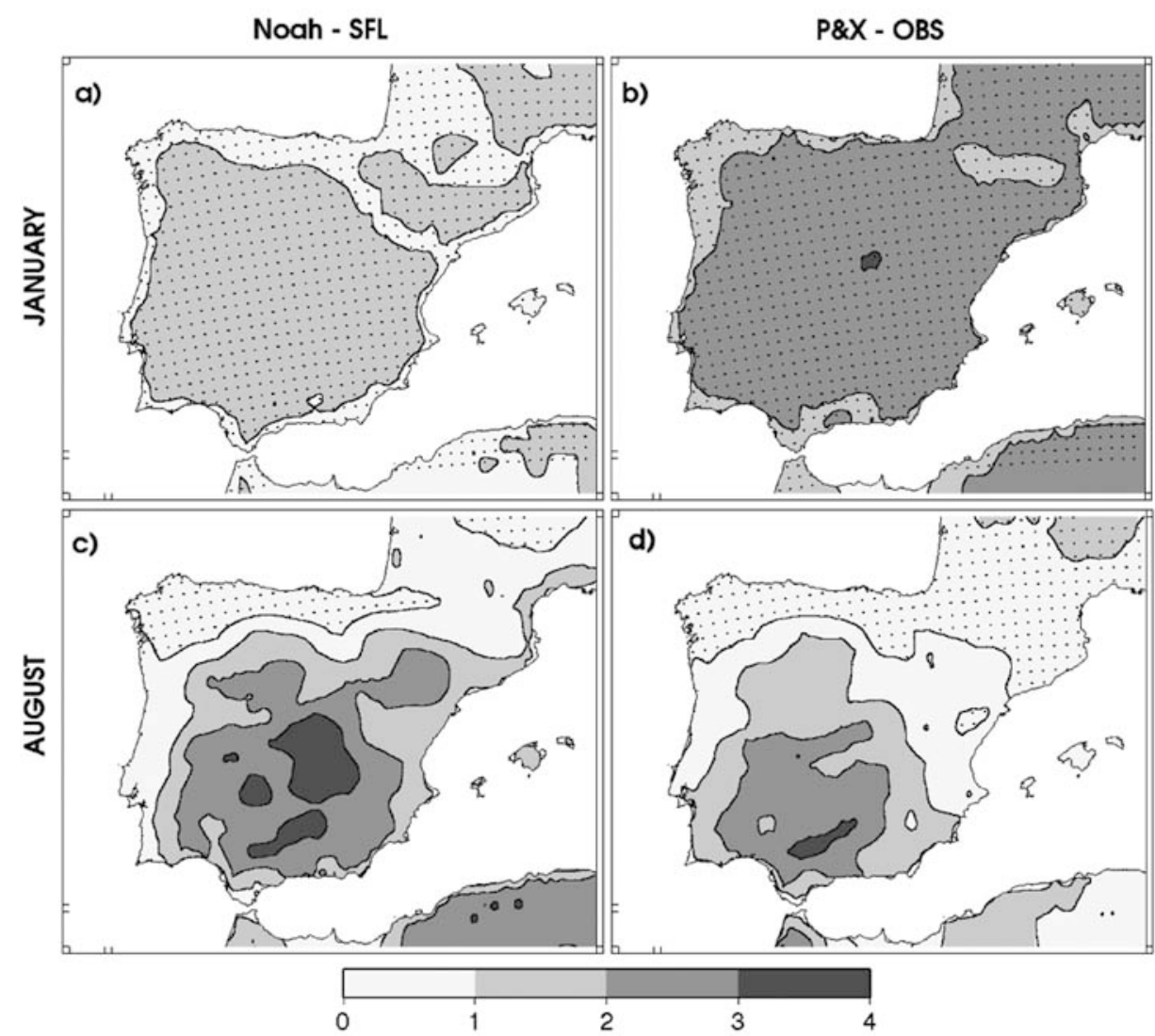

Figure 3: Differences between simulations in the T2M climatologies of January (top) and August (bottom). Noah minus SFL (left column) and P\&X minus SFL (right). Contour interval is 1 kelvin. Stippling means negative values. Averaged period 1958-2002. 


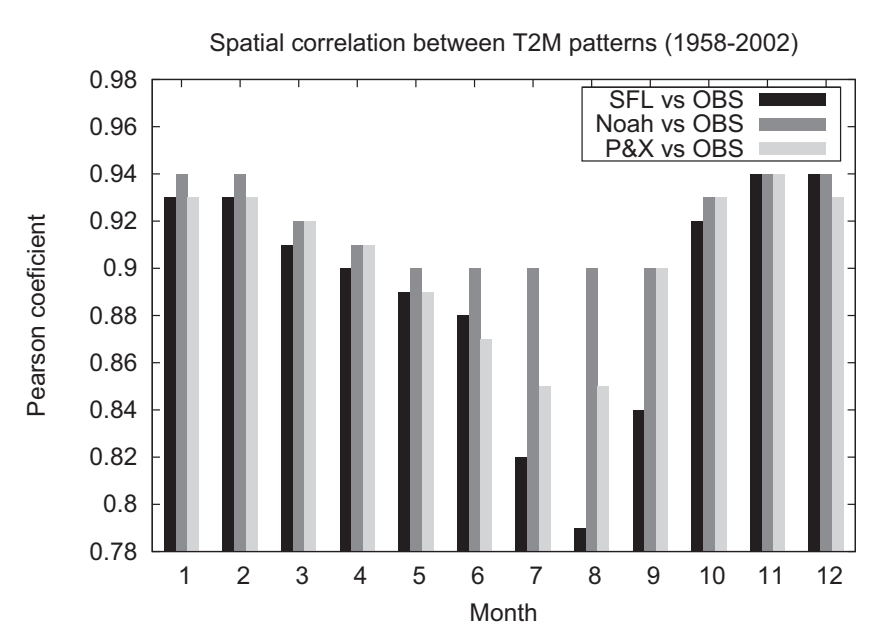

Figure 4: Spatial correlation between simulated and observed patterns of monthly mean T2M. Averaged period 1958-2002.

soil water content. The temperature at the lower boundary (assumed to be $3 \mathrm{~m}$ below the ground surface) is specified by the annual mean surface air temperature (data source: 1 degree ECMWF analysis, Uppala et al., 2005). The diffusive form of Richard's equation is used as the prognostic equation for the volumetric soil moisture content, where the hydraulic conductivity and the soil water diffusivity are also functions of the soil water content. Sources and sinks are taken into account. The total evaporation has three contributions: direct evaporation from the top shallow soil layer, evaporation of the precipitation intercepted by the canopy, and transpiration via canopy and roots. The vegetation fraction is taken into account in these formulations (data source: 10' AVHRR (CRACKNELL, 1997), containing 12 percentage-values for 12 months at each of lat/lon grid points). Landuse/vegetation category is specified from 25 -category $30^{\prime \prime}$ data from USGS version 2 land cover data (LovELAND et al., 2000). Soil thermal properties also depend on soil type (assigned to each cell from a $30^{\prime \prime} 17$-categories data base). A simple snow and sea ice model is included.

- Pleim \& Xiu Model (P\&X; XIU and Pleim, 2001). This model differs conceptually from those described above. Only two soil layers are considered, a thin (1 cm thick) surface layer, and a 1-m deep reservoir layer. The zero flux condition is imposed at the bottom for both temperature and moisture content prognostic algorithms. Soil temperature is calculated through the force restore method (BLACKADAR, 1976). For the evolution of soil moisture the same contributions as in Noah LSM are taken into account. Evaporation parameterization is also conceptually analogous to the Noah scheme.

\section{Results}

This sensitivity study deals with the capability of the simulations to reproduce the mean values, i.e. the annual cycle, and the temporal variability of the 2-meter temperature (T2M) series.

\subsection{Mean values}

The accuracy of the simulations in reproducing multiyear monthly mean values of T2M (the annual temperature cycle) is evaluated. The bias errors are plotted in Figure 2. For the sake of clarity, only two representative months, January and August, are shown. An intermediate behaviour was found for the months in between. Figure 3 depicts the differences between simulations for the January and August T2M climatologies. It is important to point out that these patterns of biases or differences are exactly the same than the patterns of root mean squared error (RMSE) computed between the monthly mean temperature series (not shown). This gives strength to our analysis since guarantees that the differences obtained are constant in time.

In wintertime (Figure 2 top) SFL shows a warm bias (up to 2 degrees), which is quite homogenous spatially. Only some coastal points differ from the rest and present a cold bias, perhaps due to the poorly captured softening effect of the sea. Noah and P\&X are colder than SFL everywhere (Figure 3 top). In neither case do the differences with respect to SFL simulation present intense spatial gradients, although they decrease on the coasts due to the homogenizing effect of the sea. The difference between P\&X and SFL (between 2 and 3 degrees) is larger than the difference between Noah and SFL (between 1 and 2 degrees). Hence, $P \& X$ show a cold bias at every point of the observational network while in the case of Noah simulation a slight warm bias remains at some points.

The bias errors are larger in summer (Figure 2 bottom) than in winter. There is also a greater disparity between simulations, especially because the patterns of differences show greater spatial variations (Figure 3 bottom). SFL strongly underestimates temperature inland and towards the south of the IP, where the bias error reaches values of more than 5 degrees (Figure 2d), as previously found by FERNANDEZ et al. (2007). The spatial patterns of differences between Noah and SFL and between P\&X and SFL are characterized by a mixture of north-south and continental gradients. Both Noah and P\&X simulations are warmer than SFL (even more than 3 degrees), except for the Cantabrian strip (northern IP), being Noah warmer than P\&X. Hence, the more complex LSMs notably reduce and homogenize the error patterns (Figures 2e and 2f), with Noah LSM performing best.

Figure 4 clarifies when and to what extent Noah and P\&X LSMs improve the reproduction of the spatial distribution of the T2M patterns in terms of spatial correlations with the observed patterns. While SFL simulation presents a strong annual cycle reaching the lowest 


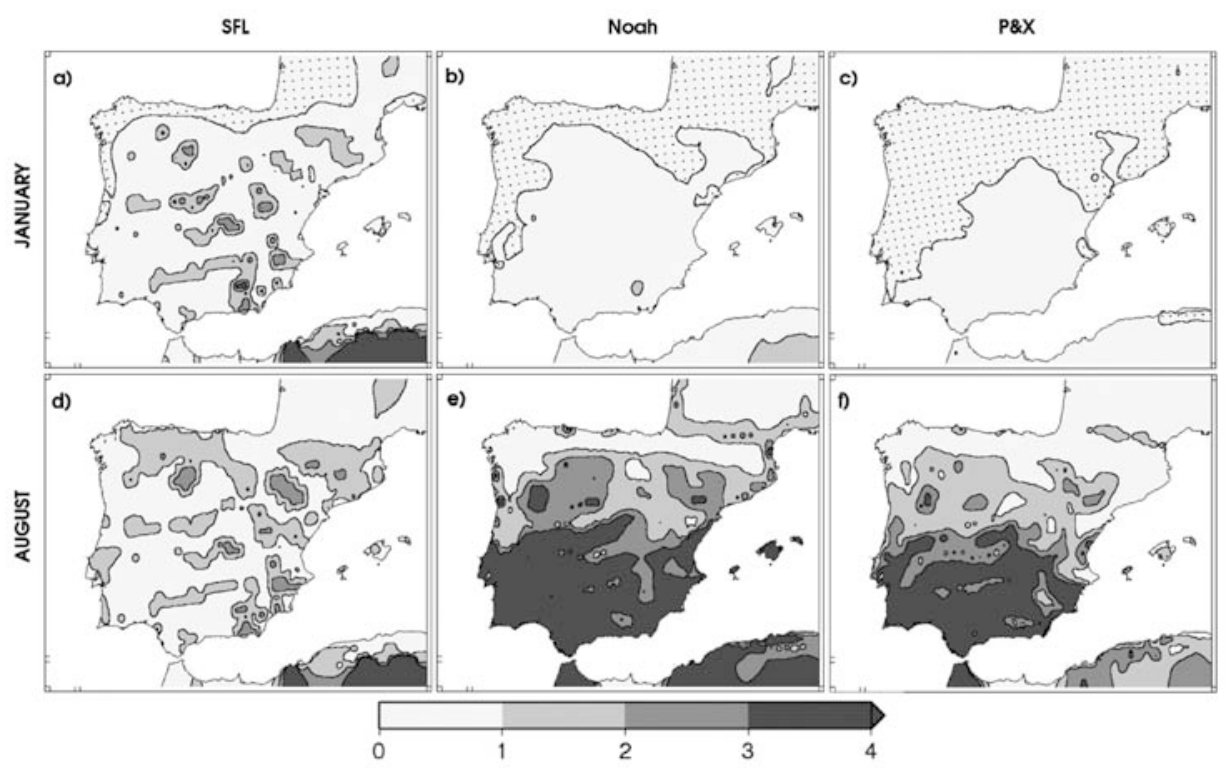

Figure 5: Patterns of Bowen ratio computed by dividing the monthly climatologies of superfical sensible and latent heat fluxes simulated by SFL (left column), Noah (centre) and P\&X (right) experiments for January (top) and August (bottom). Contour interval 1 (dimensionless). Stippling means negative values. Averaged period 1958-2002.

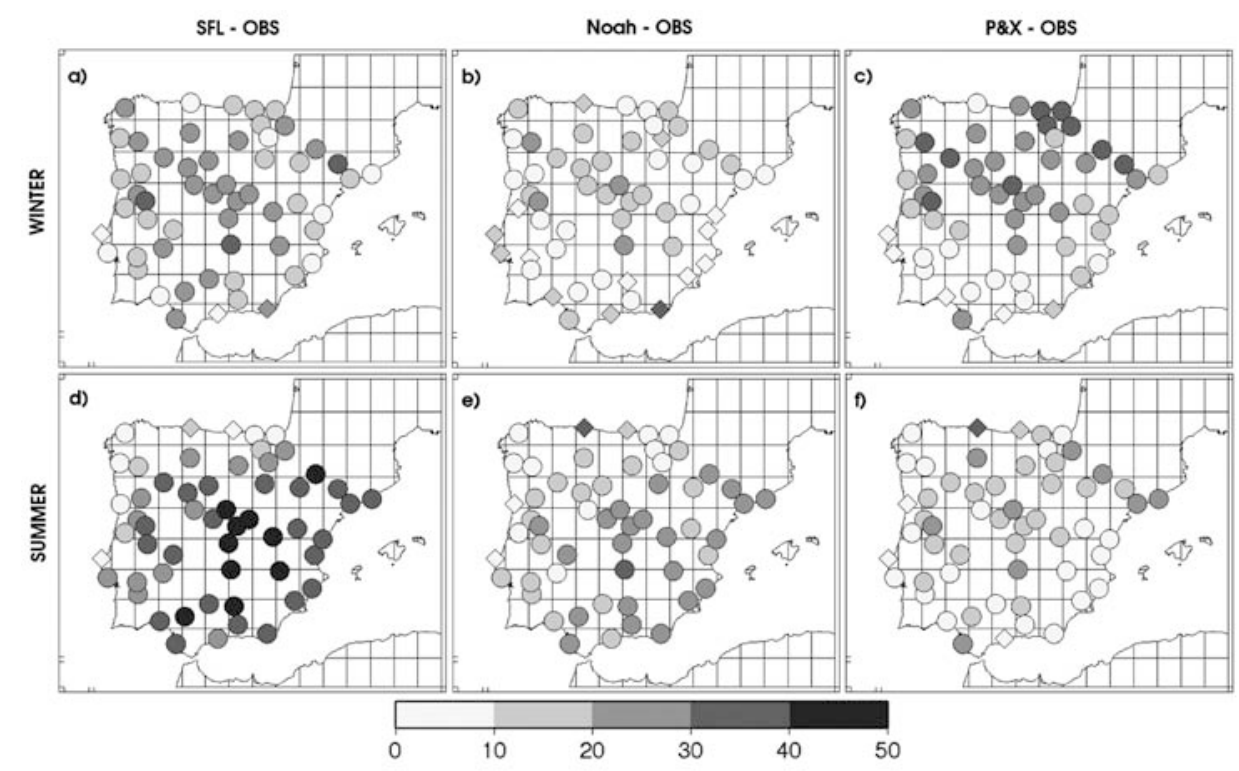

Figure 6: Differences between simulations and observations in $\sigma$ (standard deviation of the series of monthly mean T2M anomalies) for winter (top) and summer (bottom). SFL minus OBS (left column), Noah minus OBS (centre) and P\&X minus OBS (right). Differences are given in percentage with respect to the observed values. Positive differences are represented by diamonds and negative by circles. Period 1958-2002.

values in summer, $\mathrm{P} \& \mathrm{X}$ and especially Noah are better spatially correlated with the observations in summer reducing such monthly dependence. In the case of Noah, the correlation is never under 0.9 .

In summary, Noah and $\mathrm{P} \& \mathrm{X}$ simulations present a more constant bias error throughout the year because of the reduction of the cold bias in summer and the fact that the bias errors in winter are also negative. They not only reduce biases but also reproduce more realistic spatial patterns. Noah presents lower biases and better spatial correlations than $\mathrm{P} \& \mathrm{X}$. The main improvements concern the southern IP in summer.

The climatological differences between the dry/southern and the wet/northern areas of the IP lead to a north-south gradient of temperature, especially in summer (FONT-TULLOT, 2000). As has been shown, this is poorly reproduced by SFL, while Noah and $\mathrm{P} \& \mathrm{X}$ are better at capturing such spatial heterogeneity. In order to 


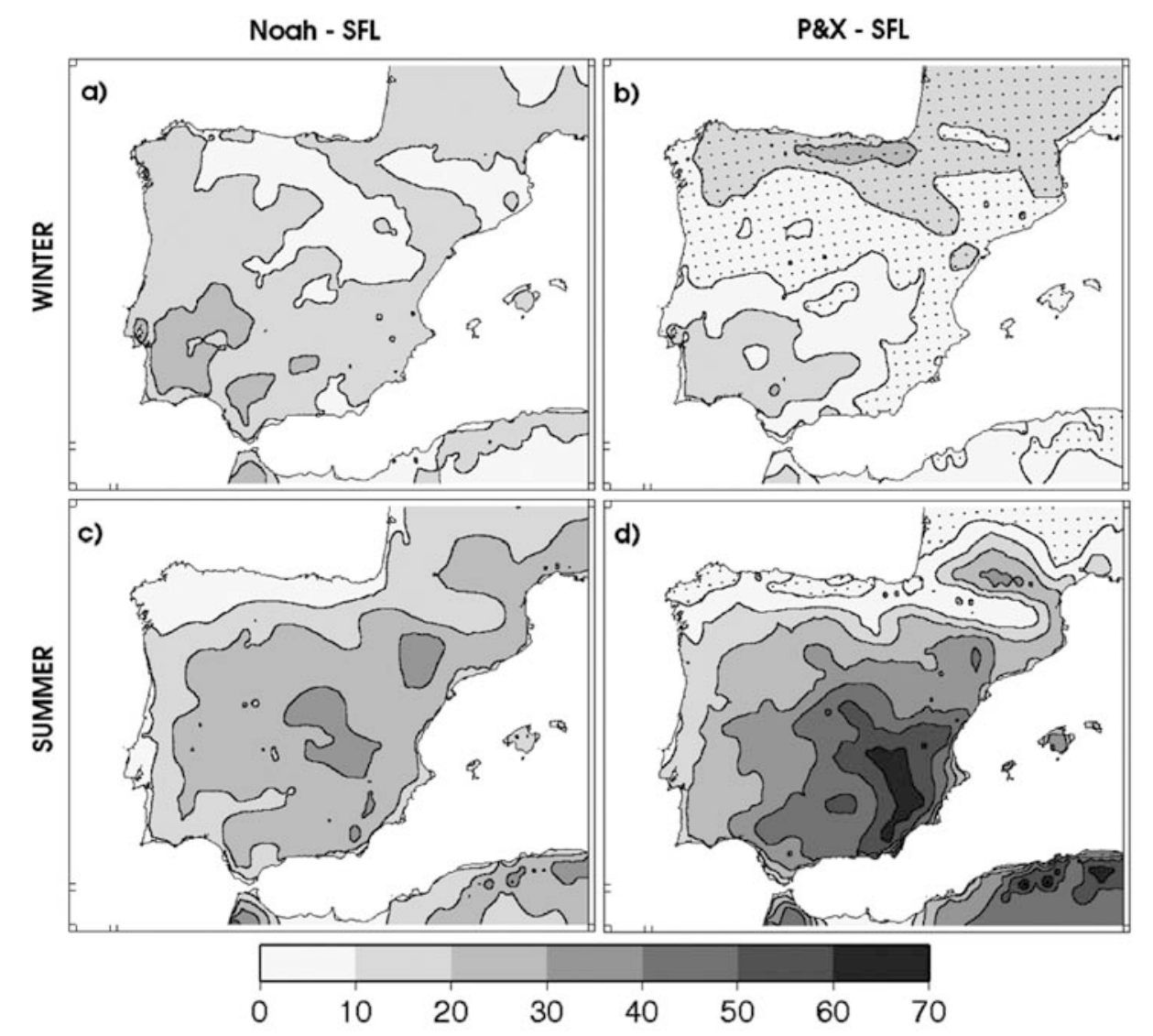

Figure 7: Differences between simulations in $\sigma$ (standard deviation of the series of monthly mean T2M anomalies) for winter (top) and summer (bottom). Noah minus SFL (left column) and P\&X minus SFL (right). Differences are given in percentage with respect to the values from SFL simulation. Contour interval is 10. Stippling means negative values. Period 1958-2002.

explain such features, we investigate simulated superficial heat fluxes. The disparity in the soil layers between the LSMs prevents a direct comparison of the soil moisture content seen or modelled by each. Nevertheless, differences in the superficial heat fluxes should reflect the differences in the available soil moisture. This analysis makes sense since the rest of the terms involved in the superficial energy balance (incoming radiation, emitted and reflected radiation and stored energy) do not show significant differences among the simulations, or at least they are orders of magnitude smaller than the differences in the superficial heat fluxes (not shown). Hence, the influence of the soil moisture is mainly manifested through its role in the partitioning of the available energy into the latent and sensible heat fluxes.

SFL leads to homogeneous patterns of the Bowen ratio (ratio between sensible and latent heat flux) at the land-atmosphere interface throughout the year (Figures $5 \mathrm{a}$ and $5 \mathrm{~d}$ ). In contrast, both Noah and P\&X simulate a larger exchange of sensible heat, to the detriment of latent heat, between the land surface and the air during summer in the southern IP (Figures 5e and 5f), where soil moisture availability usually falls severely (FONT-TULLOT, 2000). This intensification of the soil moisture-temperature feedback (manifested through the exchange of sensible heat) would explain the higher temperatures that Noah and $\mathrm{P} \& \mathrm{X}$ simulate. In fact, the Bowen ratio patterns from Noah and $P \& X$ simulations in summer match the patterns of differences in the summer T2M climatologies shown in Figure 3, although exceptions appear in coastal areas where advection phenomena may have a large influence and mask local effects. Thus, while the former were characterized by a mixture of north-south and continental gradients, only the northsouth gradient remains in the Bowen ratio patterns.

For winter, the Bowen ratio patterns from Noah and $\mathrm{P} \& \mathrm{X}$ show values of less than 1 everywhere, with a positive sign towards the south-east and negative sign towards the north-west (Figures $5 \mathrm{~b}$ and $5 \mathrm{c}$ ). In the former areas, the main difference between Noah and SFL is that Noah leads to a greater amount of energy stored in the ground, and thus to a lower exchange of sensible heat which softens the effect of the coupling between land and atmosphere. In the latter areas, the sensible heat fluxes in Noah simulation are downward (negative), i.e. the ground is colder than the air, contrary to what happens in SFL simulations. Thus, the land-atmosphere coupling contributes in this case to cool the air. It is also remarkable that the long-wave radiation that reachs the ground in winter is lower in Noah than in SFL simula- 


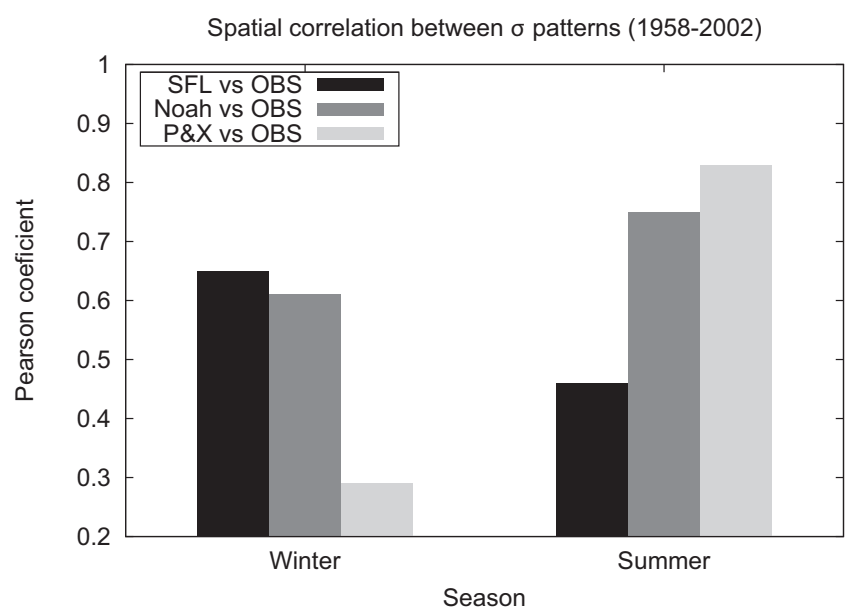

Figure 8: Spatial correlation between simulated and observed patterns of $\sigma$. Period 1958-2002.

tion. This, which points out to differences in the simulated cloudiness as reflected in the short-wave radiation that reachs the ground, also contributes to the lower temperatures obtained in the Noah simulation. These features are stronger when analyzing $P \& X$ simulation, which is in agreement with the fact that the differences in T2M between P\&X and SFL are larger than between Noah and SFL. Lower temperatures lead in both cases, Noah and P\&X simulations, to lesser latent heat fluxes.

\subsection{Temporal variability}

This section deals with the temporal variability of the simulated monthly mean temperature series. The annual cycle is removed by substracting from each monthly record the multi-year monthly mean value, and the series are splitted into extended summer (May to September inclusive) and winter (November to March), because of the different behaviour between dry/warm and wet/cold seasons.

First, the standard deviation of the series $(\sigma)$, is analyzed. The errors in $\sigma$, expressed as a percentage with respect to the observed values, are depicted in Figure 6. The standard deviation of both summer and winter series is systematically underestimated in all simulations. But there are important differences between seasons and simulations.

The spatial pattern of winter $\sigma$-errors corresponding to SFL simulation shows a quite homogeneous underestimation of around 30\% (Figure 6a). However, in summer, the largest errors (up to 50\%) are concentrated inland (Figure 6d). Hence, the spatial correlation with observations is lower for summer $(0.45)$ than for winter $(0.65)$ (Figure 8).

Noah LSM increases the temporal variability of the series compared with SFL everywhere, for both winter and summer (Figure 7 left), reducing the underestimation to below $30 \%$ in summer and $20 \%$ in winter (Figure 6 central). The added value is that, in summer, NLS introduces a greater variability precisely where SFL fails most strongly. Thus, the agreement with the observed pattern is better than in the former case and the spatial correlation is above 0.7 for summer. For winter the difference is quite negligible (Figure 8).

The comparison between $\mathrm{P} \& \mathrm{X}$ and SFL simulations shows that in winter, while $P \& X$ simulates greater variability towards the south and south-west (around 10\%), in the rest of the IP the opposite is the case (Figure 7b). Thus P\&X underestimates $\sigma$ by around $30-40 \%$ in the northern IP compared with observations (Figure 6c). This assymetry leads to a really poor reproduction of the $\sigma$ pattern in winter, which is uncorrelated with the observed pattern (Figure 8). Nevertheless, in summer, $\mathrm{P} \& \mathrm{X}$ increases the standard deviation of the series up to $70 \%$ with respect to SFL. The differences between $\mathrm{P} \& \mathrm{X}$ and SFL show a strong northwest-southeast gradient (Figure 7d). Although such a distribution does not exactly fit the error pattern of SFL (shown in Figure 6d), the spatial correlation between the $\sigma$-patterns of P\&X and OBS is above 0.8 in summer, which is the best value (Figure 8).

In summary, both Noah and $P \& X$ largely increase the variability of the temperature series in summer, and improve the spatial distribution of the $\sigma$-patterns. For winter, the balance is positive only in the case of Noah.

In order to investigate the underlaying mechanisms for the above results, the temporal correlation between series of differences of temperature anomalies, $T_{\text {Noah }}^{\prime}$ $T_{S F L}^{\prime}$ or $T_{P \& X}^{\prime}-T_{S F L}^{\prime}$, and series of anomalies in the soil moisture content in the root zone, $S M_{N o a h}^{\prime}$ or $S M_{P \& X}^{\prime}$ respectively, is computed. The subscripts refer to the corresponding simulation. These results are shown in Figure 9. Significant values are found only for summer, where the negative correlations mean that a negative soil moisture anomaly leads to a higher temperature anomaly in Noah and in P\&X than in the SFL series, and vice versa. In the case of Noah simulation it can be concluded that the higher standard deviation of the summer series is clearly related to the modelled soil moisture evolution, since patterns of Figures $6 \mathrm{~d}$ and $9 \mathrm{c}$ match. However, in the case of $\mathrm{P} \& \mathrm{X}$ simulation this relation is not clear perhaps due to the different approaches to represent the PBL processes, whose influence is out of the scope of this work.

Finally, we analyze the temporal correlation between simulated and observational series of temperature anomalies (Figure 10). Surprisingly, the SFL series show the best agreement with observations. In winter, the SFL series are highly correlated with the observed series everywhere (over 0.85) (Figure 10a), while for summer a northwest-southeast gradient appears (Figure 10d), reaching the lowest values towards the southeastern IP (0.6-0.7). Noah (Figure 10 centre) and P\&X (Figure 10 right) show very similar results to SFL.

The correlation between the Noah and SFL series indicates good agreement, always above 0.9 (Figure 11 left). Between P\&X and SFL (Figure 11 right) agreement is also good for winter, but for summer the pattern 

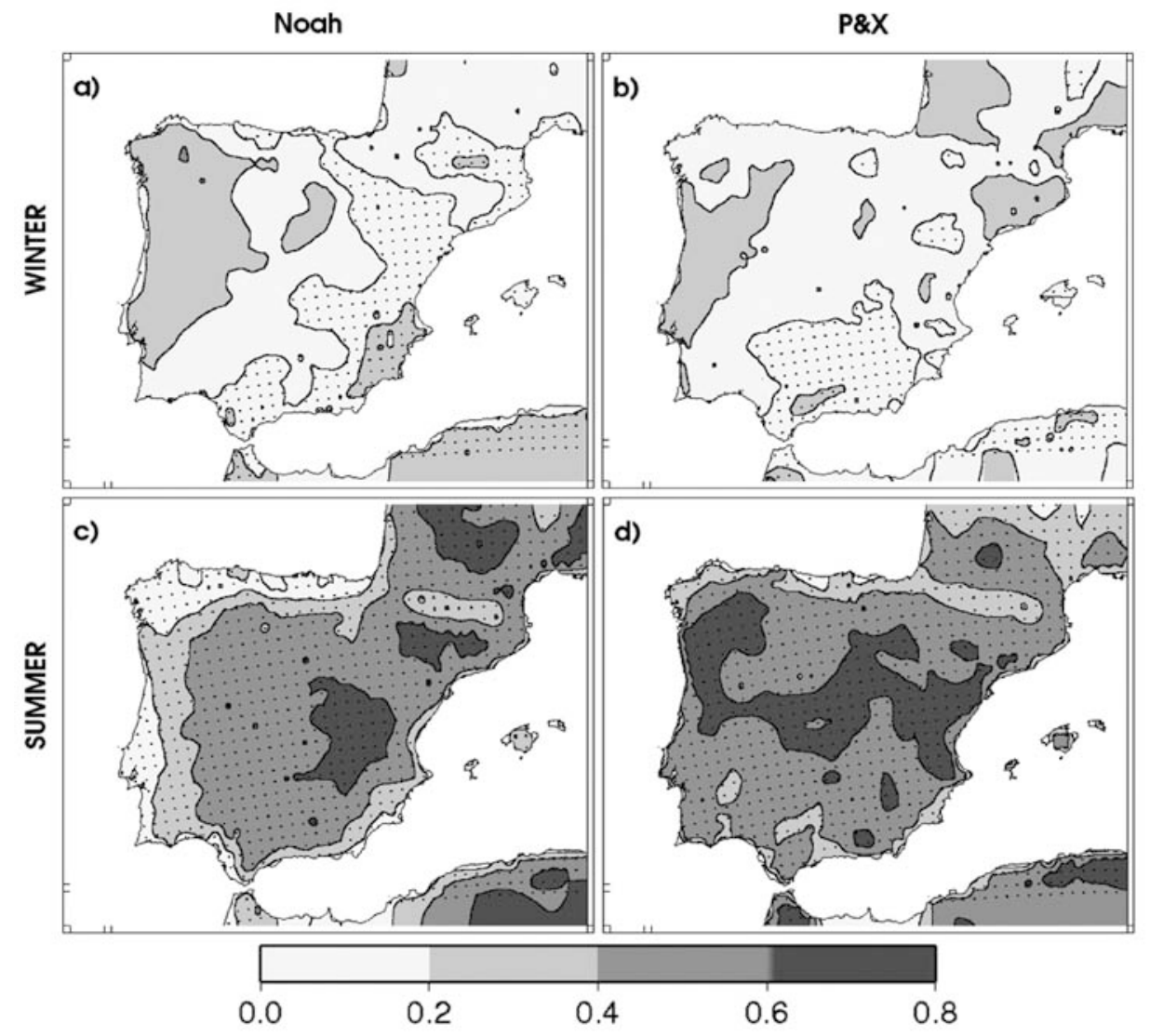

Figure 9: Temporal correlation between series of $\mathrm{SM}^{\prime}$ and $\Delta \mathrm{T}_{2} \mathrm{M}^{\prime}$ for winter (top) and summer (bottom). $\mathrm{T} 2 \mathrm{M}^{\prime}$ means $\mathrm{T} 2 \mathrm{M}$ anomaly (the monthly value minus the climatology of the corresponding month). $\Delta \mathrm{T}_{2} \mathrm{M}^{\prime}$ denotes differences in T2M' between Noah and SFL (left column) or between P\&X and SFL (right column) simulations. SM' denotes anomaly of soil moisture content in the root zone from Noah or P\&X simulation respectively. Contour interval is 0.2. Stippling means negative values. Period 1958-2002.

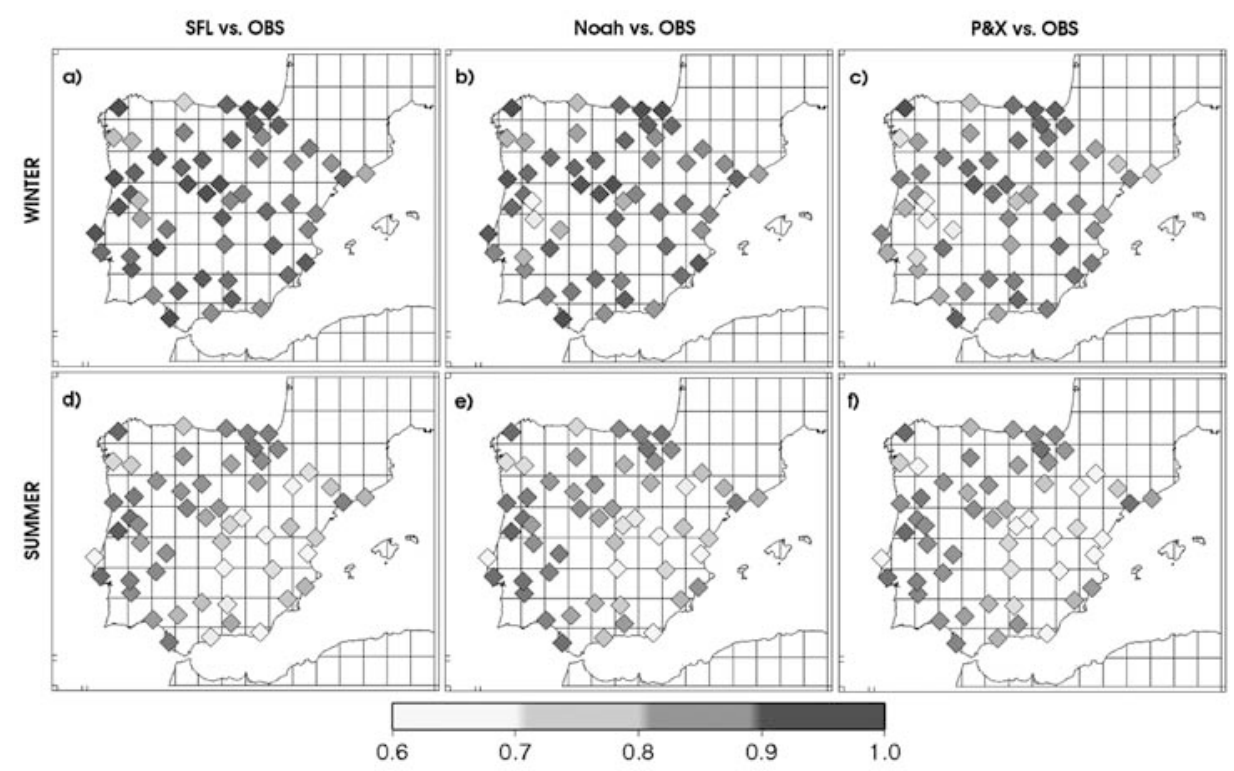

Figure 10: Temporal correlation between simulated and observed series of T2M anomalies for winter (top) and summer (bottom). SFL vs. OBS (left column), Noah vs. OBS (centre), and P\&X vs. OBS (right). Diamonds mean positive values. Period 1958-2002. 


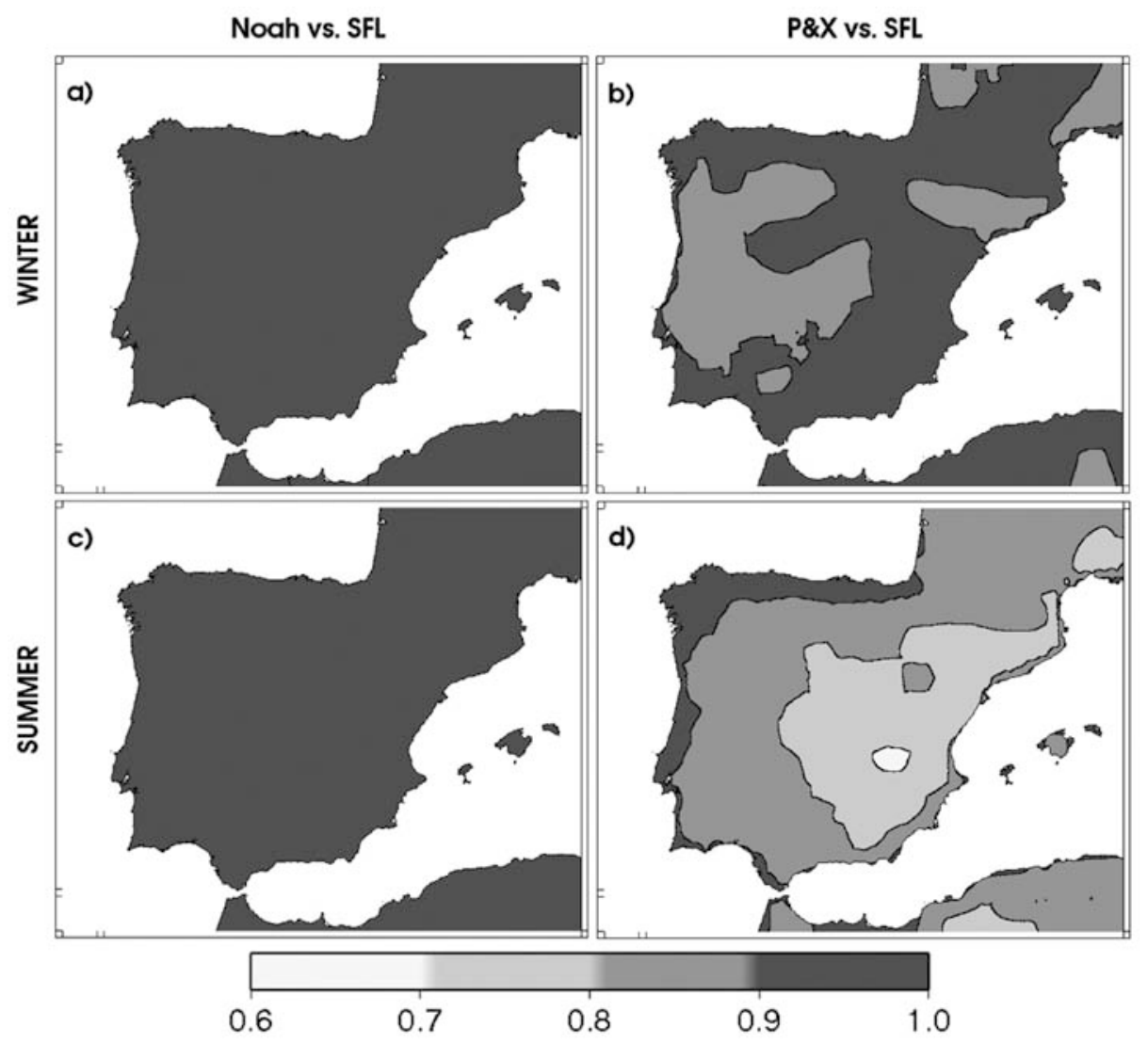

Figure 11: Temporal correlation between simulated series of T2M anomalies for winter (top) and summer (bottom). Noah vs. SFL (left column) and P\&X vs. SFL (right). Contour interval is 0.1. Period 1958-2002.

of P\&X-SFL correlations shows a northwest-southeast gradient and the values fall to 0.7 . This pattern matches the pattern of differences between P\&X and SFL in $\sigma$ (Figure $7 \mathrm{~d}$ ). Thus, where $\mathrm{P} \& \mathrm{X}$ introduces a larger variability in the temperature series, the temporal correlation with the SFL series is lower.

These last results lead to the following conclusions. First, neither Noah nor P\&X improves the correlation with the observational series of temperature. Since there is strong agreement between Noah and SFL series (correlations above 0.9), Noah basically introduces higher variability. The agreement between $P \& X$ and SFL is poorer, especially for the summer series, when $\mathrm{P} \& \mathrm{X}$ not only introduces a higher variability but also its own distinctive variability of the temperature series.

\section{Comments and conclusions}

This work assesses the ability of regional climate simulations to reproduce mean values and temporal variability of near-surface air temperature over the Iberian Peninsula when different approaches to represent land surface-atmosphere interactions are employed within the same RCM.
MM5 allows different soil-atmosphere couplings. Those tested here are SFL-MRF, Noah-MRF and P\&XP\&C (denoted as LSM-PBL parameterizations). The main difference between SFL and the other LSMs is that SFL prescribes soil moisture content to fixed values while Noah and P\&X treat soil moisture dynamically.

First, the accuracy of the simulations when reproducing the annual temperature cycle was evaluated. The major weakness of SFL is a strong cold bias in summer, reaching more than 5 degrees inland and toward the southern IP (FERNANDEZ et al., 2007). This error is largely overcome (by about 50\%) using Noah or P\&X. These more complex LSMs better capture the spatial differences between northern and southern IP in summertime and provides more realistic temperature spatial patterns. Their capability to simulate an evolving soil moisture content, and thus more realistic superficial heat fluxes (SRIDHAR et al., 2002), provides a satisfactory explanation of such improvements. In wintertime, differences among simulations are smaller than in summer. SFL slightly overestimates winter temperature, while Noah and P\&X underestimates it. Such different bias-signs have been linked to differences in the energy stored in the ground. In general both, Noah and P\&X, improve the reliability of the simulations when reproducing the annual temperature cycle, leading to a more 
constant and smaller bias error throughout the year and a better reproduction of the spatial patterns. Noah provides the best confidence.

Second, the standard deviation of the series of monthly mean temperature anomalies (splitted into extended summer and winter months) was analyzed. This magnitude is systematically underestimated. Such underestimation is again larger in the case of SFL simulation for summer in points of inland and southern IP, reaching values of up to $50 \%$. Noah and P\&X notably increase the variability of the summer series and provide a better reproduction of the spatial patterns. An evolving soil moisture content is again determinant for these improvements (SENEVIRATNE et al., 2006), although such attribution is masked in the case of $\mathrm{P} \& \mathrm{X}$ simulation due to the different PBL scheme used. Although P\&X performs best in summertime, in winter it shows the worst accuracy. However, Noah shows a similar performance for both summer and winter. On the other hand, temporal correlations are not strongly affected by the selection of the LSM. Thus, the more complex LSMs basically introduce greater variability in the series of temperature anomalies.

Between Noah or $\mathrm{P} \& \mathrm{X}$, these results indicate that the best confidence is provided by coupling Noah LSM to MM5. Although P\&X shows better accuracy than Noah occasionally, especially as regards the standard deviation of the summer series, it fails even more than SFL in winter and shows lower consistency in the improvements than Noah.

This intercomparison allowed us to discriminate areas and seasons in which the temperature sensitivity to the LSM is strongest. The largest differences between SFL and the two other LSMs appeared in summer, when local circulations became more important than large scale advection phenomena, and in the inner and southern IP, where the scarce precipitation causes severe droughts, whose effects are inhibited if the soil moisture is not allowed to evolve.

Since soil processes are found to have a great influence, the realism of the soil characterization could also be expected to have a large impact (PIELKE et al., 1999; MARShALl et al., 2004; OSBORNE et al., 2004). In these simulations, parameters such as heat capacity, soil moisture content saturation, vegetation fraction, etc., are given by the land use category. These parameters appear in the soil processes formulations and play determinant roles. Thus, a realistic data base of land uses and the associated parameters would be of great importance.

Finally, it has been shown that the soil moisturetemperature feedback leads to warmer and more uneven summers in the present climate simulations, and the question that arises is how and to what extent such interaction would influence regional projections of climate change. Although some studies deal with this question (i.e. SENEVIRATNE et al., 2006), this topic is still poorly reported.

\section{Acknowledgments}

This work was funded by the Spanish Ministry of the Environment (project ESCENA, Ref. 20080050084265) and the Spanish Ministry of Science and Technology (project INVENTO-CGL2005-06966-C07-04/CLI). The authors also gratefully acknowledge the funding from the Euro-Mediterranean Institute of Water (IEA). Thanks to Christina SCHWARZ for the abstract translation.

\section{References}

Beck, A., B. Ahrens, K. Stadlbacher, 2004: Impact of nesting strategies in dynamical downscaling of reanalysis data. - Geophys. Res. Lett. 31, L19101.

BLACKADAR, A. K., 1976: Modeling nocturnal boundarylayer. - Bull. Amer. Meteor. Soc. 57, 631.

Boo, K., W. Kwon, H. BAEK, 2006: Change of extreme events of temperature and precipitation over Korea using regional projection of future climate change. - Geophys. Res. Lett. 33, L01701.

Chen, F., J. DudhiA, 2001a: Coupling an advanced land surface-hydrology model with the Penn State-NCAR MM5 modeling system. Part I: Model implementation and sensitivity. - Mon. Wea. Rev. 129, 569-585.

Chen, F., J. Dudhia, 2001b: Coupling an advanced land surface-hydrology model with the Penn State-NCAR MM5 modeling system. Part II: Preliminary model validation. Mon. Wea. Rev. 129, 587-604.

CRACKNELl, A., 1997: The Advanced Very High Resolution Radiometer. - London, Taylor \& Francis.

DudHIA, J., 1989: Numerical study of convection observed during the winter monsoon experiment using a mesoscale two-dimensional model. - J. Atmos. Sci. 46, 3077-3107.

DuDHIA, J., 1996: A multi-layer soil-temperature model for MM5. - In: Preprint, Sixth PSU/NCAR Mesoscale Model Users Workshop, 49-50, Boulder, CO.

FERnANDEZ, J., J.P. MontaVez, J. SAEnZ, J.F. GONZALEZ-ROuCO, E. ZORITA, 2007: Sensitivity of the MM5 mesoscale model to physical parameterizations for regional climate studies: Annual cycle. - J. Geophys. Res.-Atmos. 112(D4) D04101.

Fischer, E. M., S. I. Seneviratne, D. Luethi, C. SCHAER, 2007: Contribution of land-atmosphere coupling to recent European summer heat waves. - Geophys. Res. Lett. 34 L06707.

FonT-Tullot, I., 2000: Climatología de España y Portugal - Ediciones Universidad de Salamanca, Spain.

Frank, H., L. LANDBERG, 1997: Modelling the wind climate of Ireland. - Bound.-Lay. Meteoror. 85, 359-378.

Gomez-Navarro, J., J. Montavez, P. JimeneZGUERRERO, S. JEREZ, J. GARCIA-VALERO, J. GonZALEZ-RoucO, 2010: Warming patterns in regional climate change projections over the Iberian Peninsula. - Meteorol. Z. 19, 275-285.

GrELL, G.A., 1993: Prognostic evaluation of assumptions used by cumulus parameterizations. - Mon. Wea. Rev. 121, 764-787.

Grell, G.A., J. DudhiA, D.R. Stauffer, 1994: A description of the fifth-generation Penn State/NCAR Mesoscale Model (MM5). - Technical Report NCAR/TN398+STR, National Center for Atmospheric Research. 
Henderson-Sellers, A., P. Irannejad, K. McGuffie, A. PItMan, 2003: Predicting land-surface climates better skill or moving targets?. - Geophys. Res. Lett. 30, 1777.

Hong, S., H. PAN, 1996: Nonlocal boundary layer vertical diffusion in a Medium-Range Forecast Model. - Mon. Wea. Rev. 124, 2322-2339.

IM, E. S., W. J. Gutowski, JR., F. Giorgi, 2008: Consistent changes in twenty-first century daily precipitation from regional climate simulations for Korea using two convection parameterizations. - Geophys. Res. Lett. 35 L14706.

Irannejad, P., A. Henderson-Sellers, S. SharmeEn, 2003: Importance of land-surface parameterization for latent heat simulation in global atmospheric models. Geophys. Res. Lett. 301904.

JUANG, H., S. Hong, 2001: Sensitivity of the NCEP regional spectral model to domain size and nesting strategy. - Mon. Wea. Rev. 129, 2904-2922.

Koster, R., P. Dirmeyer, Z. Guo, G. Bonan, E. Chan, P. Cox, C. Gordon, S. Kanae, E. KowalczyK, D. LAwrence, P. LiU, C. LU, S. MalysheV, B. MCAVANEy, K. Mitchell, D. Mocko, T. OKI, K. Oleson, A. Pitman, Y. Sud, C. TAYlor, D. Verseghy, R. VASIC, Y. XUE, T. YAMADA, GLACE TEAM, 2004: Regions of strong coupling between soil moisture and precipitation. - Science 305, 1138-1140.

Lionello, P., U. Boldrin, F. Giorgi, 2008: Future changes in cyclone climatology over Europe as inferred from a regional climate simulation. - Climate Dynam. 30, 657-671.

Loveland, T., B. Reed, J. Brown, D. Ohlen, Z. ZhU, L. YAnG, J.W. Merchant, 2000: Development of a global land cover characteristics database and IGBP DISCover from $1 \mathrm{~km}$ AVHRR data. - Int. J. Remote Sens. 21, 1303-1330.

Luo, Y., E.H. Berbery, K.E. Mitchell, A.K. Betts, 2007: Relationships between land surface and near-surface atmospheric variables in the NCEP north American regional reanalysis. - J. Hydrometeorol. 8, 1184-1203.

Manabe, S., 1969: Climate and ocean circulation. I. Atmospheric circulation and hydrology of earths surface. - Mon. Wea. Rev. 97, 739-774.

Marshall, C., R. Pielke, L. Steyaert, D. Willard, 2004: The impact of anthropogenic land-cover change on the Florida peninsula sea breezes and warm season sensible weather. - Mon. Wea. Rev. 132, 28-52.

MiaO, J. F., D. Chen, K. Borne, 2007: Evaluation and comparison of Noah and Pleim-Xiu land surface models in MM5 using GOTE2001 data: Spatial and temporal variations in near-surface air temperature. - J. Appl. Meteor. Climatol. 46, 1587-1605.

Mlawer, E., S. Taubman, P. Brown, M. Iacono, S. ClOUGH, 1997: Radiative transfer for inhomogeneous atmospheres: RRTM, a validated correlated-k model for the longwave. - J. Geophys. Res.-Atmos. 102, 16663-16682.

Monaghan, A.J., D.H. BRomwiCh, W. Chapman, J.C. COMISO, 2008: Recent variability and trends of Antarctic near-surface temperature. - J. Geophys. Res.-Atmos. 113(D4) D04105.
Osborne, T., D. LaWrence, J. Slingo, A. Challinor, T. WHEELER, 2004: Influence of vegetation on the local climate and hydrology in the tropics: sensitivity to soil parameters. - Climate Dynam. 23, 45-61.

PAN, Z., M. SEgal, R. ARritt, E. TAKLE, 2004: On the potential change in solar radiation over the US due to increases of atmospheric greenhouse gases. - Renewable Energy 29, 1923-1928.

PIELKE, R., 2001: Influence of the spatial distribution of vegetation and soils on the prediction of cumulus convective rainfall. - Rev. Geophys. 39, 151-177.

Pielke, R., G. Liston, J. EAstman, L. Lu, M. Coughenour, 1999: Seasonal weather prediction as an initial value problem. - J. Geophys. Res.-Atmos. 104(D16), 19463-19479.

Pitman, A., 2003: The evolution of, and revolution in, land surface schemes designed for climate models. - Int. J. Climatol. 23, 479-510.

Pleim, J. E., A. XIU, 1995: Development and testing of a surface flux and planetary boundary-layer model for application in mesoscale models. - J. Appl. Meteor. 34, 16-32.

Pryor, S., R. BArthelmie, E. KJellstrom, 2005: Potential climate change impact on wind energy resources in northern Europe: analyses using a regional climate model. - Climate Dynam. 25, 815-835.

Seneviratne, S. I., D. Luethi, M. Litschi, C. Schaer, 2006: Land-atmosphere coupling and climate change in Europe. - Nature 443, 205-209.

SRidhar, V., R. Elliott, F. Chen, J. Brotzge, 2002: Validation of the NOAH-OSU land surface model using surface flux measurements in Oklahoma. - J. Geophys. Res.-Atmos. 107, D20, 4418.

STEnsRud, D., 2007: Parameterization schemes. - Cambridge University Press, UK.

Uppala, S., P. Kallberg, A. Simmons, U. Andrae, V. Bechtold, M. Fiorino, J. Gibson, J. HASEler, A. Hernandez, G. Kelly, X. Li, K. OnOGi, S. SAARINen, N. Sokka, R. Allan, E. Andersson, K. Arpe, M. Balmaseda, A. BeljaArs, L. VAN De Berg, J. Bidlot, N. Bormann, S. Caires, F. ChevalLier, A. Dethof, M. Dragosavac, M. Fisher, M. Fuentes, S. Hagemann, E. Holm, B. Hoskins, L. Isaksen, P. Janssen, R. Jenne, A. MCNally, J. Mahfouf, J. Morcrette, N. Rayner, R. SAunDers, P. Simon, A. Sterl, K. Trenberth, A. Untch, D. VAsiljevic, P. Viterbo, J. Woollen, 2005: The ERA-40 re-analysis. - Quart. J. Roy. Meteor. Soc. 131, 2961-3012.

XIU, A., J. Pleim, 2001: Development of a land surface model. Part I: Application in a mesoscale meteorological model. - J. Appl. Meteor. 40, 192-209.

ZHANG, J., W.-C. WANG, J. WEI, 2008: Assessing landatmosphere coupling using soil moisture from the Global Land Data Assimilation System and observational precipitation. - J. Geophys. Res.-Atmos. 113, D17, pages??.

ZHU, J., X.-Z. LiANG, 2007: Regional climate model simulations of US precipitation and surface air temperature during 1982-2002: Interannual variation. - J. Climate 20, 218-232. 